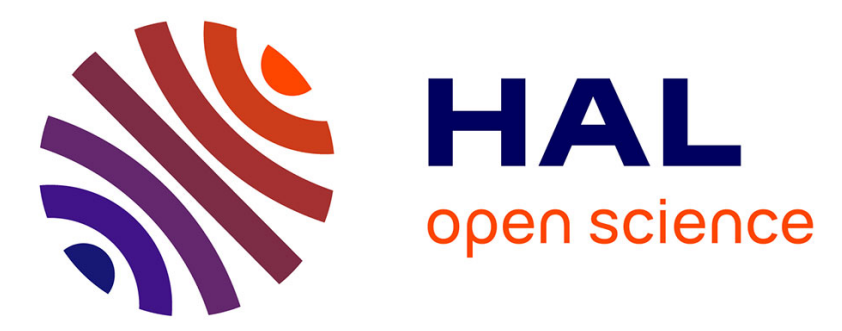

\title{
An a posteriori species clustering for quantifying the effects of species interactions on ecosystem functioning
}

Benoît Jaillard, Camille Richon, Philippe Deleporte, Michel Loreau, Cyrille

Violle

\section{- To cite this version:}

Benoît Jaillard, Camille Richon, Philippe Deleporte, Michel Loreau, Cyrille Violle. An a posteriori species clustering for quantifying the effects of species interactions on ecosystem functioning. Methods in Ecology and Evolution, 2018, 9 (3), pp.704-715. 10.1111/2041-210X.12920 . hal-02350549

\author{
HAL Id: hal-02350549 \\ https://hal.science/hal-02350549
}

Submitted on 26 May 2020

HAL is a multi-disciplinary open access archive for the deposit and dissemination of scientific research documents, whether they are published or not. The documents may come from teaching and research institutions in France or abroad, or from public or private research centers.
L'archive ouverte pluridisciplinaire HAL, est destinée au dépôt et à la diffusion de documents scientifiques de niveau recherche, publiés ou non, émanant des établissements d'enseignement et de recherche français ou étrangers, des laboratoires publics ou privés.

\section{(c)(1)}

Distributed under a Creative Commons Attribution| 4.0 International License 


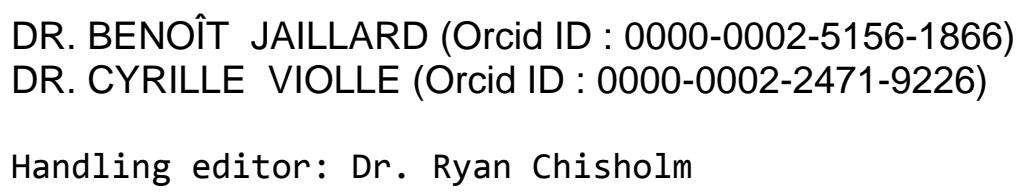

Article type : Research Article

Title: An a posteriori species clustering for quantifying the effects of species interactions on ecosystem functioning

Running title: Species interactions and ecosystem functioning

\section{Names of the authors:}

Benoît Jaillard

Inra, UMR1222 Ecologie fonctionnelle et Biogéochimie des Sols et Agrosystèmes (Eco\&Sols), 2 place Pierre Viala, 34060 Montpellier, France.

benoit.jaillard@inra.fr

\section{Camille Richon}

Inra, UMR1222 Ecologie fonctionnelle et Biogéochimie des Sols et Agrosystèmes (Eco\&Sols), 2 place Pierre Viala, 34060 Montpellier, France.

Current address: Laboratoire des Sciences du Climat et de I'Environnement, CEA Orme des Merisiers, bâtiment 712, 91191 Gif-sur-Yvette, France.

camille.richon@lsce.ipsl.fr

\section{Philippe Deleporte}

Cirad, UMR1222 Ecologie fonctionnelle et Biogéochimie des Sols et Agrosystèmes

This article has been accepted for publication and undergone full peer review but has not been through the copyediting, typesetting, pagination and proofreading process, which may lead to differences between this version and the Version of Record. Please cite this article as doi: 10.1111/2041-210X.12920

This article is protected by copyright. All rights reserved. 
(Eco\&Sols), 2 place Pierre Viala, 34060 Montpellier, France.

philippe.deleporte@cirad.fr

Michel Loreau, Centre for Biodiversity Theory and Modelling, Theoretical and Experimental Ecology Station, CNRS and Paul Sabatier University, 09200 Moulis, France.

michel.Ioreau@cnrs.fr

Cyrille Violle, UMR 5175, Centre d'Ecologie Fonctionnelle et Evolutive (CEFE), CNRS Université de Montpellier - Université Paul Valéry - EPHE, 1919 route de Mende, 34293 Montpellier Cedex 5, France

cyrille.violle@cefe.cnrs.fr

\section{Abstract}

1. Quantifying the effects of species interactions is key to understanding the relationships between biodiversity and ecosystem functioning but remains elusive due to combinatorics issues. Functional groups have been commonly used to capture the diversity of forms and functions and thus simplify the reality. However, the explicit incorporation of species interactions is still lacking in functional group-based approaches. Here we propose a new approach based on an a posteriori clustering of species to quantify the effects of species interactions on ecosystem functioning.

2. We first decompose the observed ecosystem function using null models, in which species diversity does not affect ecosystem function, to separate the effects of species interactions and species composition. This allows the identification of a posteriori functional groups that have contrasting diversity effects on ecosystem functioning. We then develop a formal combinatorial model of species interactions in which an ecosystem is described as a combination of co-occurring functional groups, which we call an assembly motif. Each

This article is protected by copyright. All rights reserved. 
assembly motif corresponds to a particular biotic environment. We demonstrate the relevance of our approach using datasets from a microbial experiment and the long-term Cedar Creek Biodiversity II experiment.

3. We show that our a posteriori approach is more accurate, more efficient and more parsimonious than a priori approaches. The discrepancy between a priori and a posteriori approaches results from the way each clustering is set up: a priori approaches are based on ecosystem or species properties, such as ecosystem size (number of species or functional groups) or species' functional traits, whereas our a posteriori approach is based only on the observed interaction and composition effects on ecosystem functioning.

4. Our findings demonstrate that an a posteriori approach is highly explanatory: it identifies who interacts with whom, and quantifies the effects of species interactions on ecosystem functioning. They also highlight that a combinatorial modelling of ecosystem functioning can predict the functioning of an ecosystem without any hypothesis about the biotic or environmental determinants or any information on species functional traits. It only requires the species composition of the ecosystem and the observed functioning of others that share the same assembly motif.

Keywords: assembly motif, clustering, combinatorics, community, functional effect groups, modelling, theoretical ecology

\section{Introduction}

Species interactions strongly influence ecosystem functioning (Loreau et al. 2001; Hooper et al. 2005). However quantifying their net impact is puzzling (Huston 1997; Balvanera et al. 2006; Duffy 2009; Jiang et al. 2009). Analytical methods have been proposed to separate the net effects of species composition from those of species interactions (Wilson 1988;

This article is protected by copyright. All rights reserved. 
Garnier et al. 1997; Loreau \& Hector 2001; Kirwan et al. 2009). These methods have successfully explained biodiversity effects in several biodiversity-ecosystem functioning experiments (Loreau \& Hector 2001; Reich et al. 2012), but they have not quantified the net effect of species interactions nor identified the species that really interact. The quantification of all possible pairwise species interactions is practically infeasible in species-rich ecosystems because of the curse of dimensionality (McGill et al. 2006). The difficulty of this task lies in the fact that myriad different types of positive and negative species interactions can simultaneously occur within ecosystems. Several attempts have been proposed to frame a pragmatic and operational approach to quantify ecosystem-wide species interactions. The trait-based characterization of species' competitive abilities i.e. the search for organism traits that can explain how species' functions influence the performance of competing neighbours (Grace 1990), paved the road to a generic description of species interactions. In the last decade, this approach has been widely used to study species interactions (the "interaction milieu" sensu McGill et al. 2006) through the systematic evaluation of the community-level distribution of interaction traits. However, interaction traits are still unknown in most taxa (Violle et al. 2014).

Even if functional-group approaches simplify reality, they offer an operational and parsimonious way to analyse and model ecosystem functioning. Nevertheless, up to now this approach has mostly relied on a priori clustering based on expert knowledge, as illustrated by the widespread classification of plants into three groups: legumes, graminoids and forbs. An a posteriori clustering may be promising since it will identify functional groups based on realized effects, for instance based on the way interacting species modulate ecosystem functioning. Such clustering has hardly been applied so far. A notable exception is the study of Wright et al. (2006) which searched for the best species clustering to predict ecosystem biomass. More recently, Jaillard et al. (2014) developed a novel modelling approach to species interactions based on their effects on ecosystem functioning. This model was able to successfully reproduce all the forms of biodiversity-ecosystem functioning

This article is protected by copyright. All rights reserved. 
relationships reported in the literature but its flexibility remained low because it is based on a priori prevalent assembling rules that determine ecosystem functioning. Here we extend Jaillard et al. (2014)'s model by proposing an a posteriori clustering approach to the effects of ecosystem-wide species interactions on a given ecosystem function.

The aim of this paper is to quantify the net effects of species interactions on a given ecosystem function. As suggested by Wilson (1988), we first decompose the observed ecosystem function using null models in which species diversity does not affect ecosystem functioning. This allows us to separate the effects of species interactions from the effects of species composition on ecosystem functioning. This separation makes it possible to $a$ posteriori identify functional groups (sensu Diaz \& Cabido 2001 and Lavorel \& Garnier 2002) that have contrasting interaction and composition effects on the ecosystem function. Then we propose a formal combinatorial framework to describe an ecosystem as a combination of co-occurring functional groups, which we call assembly motif, echoing the network motifs in network theory (Milo et al. 2002). Each assembly motif parsimoniously accounts for the observed effects of species interactions and composition on ecosystem functioning. We test this approach using two datasets: one microbial diversity experiment (Langenheder et al. 2010) and the Cedar Creek Biodiversity II experiment (Tilman et al. 2001). We demonstrate that our approach can identify (the functional structure of ecosystems, i.e.) who is interacting with whom, and quantify the effects of species diversity on ecosystem functioning.

\section{Material and Methods}

\section{Separating the effects of species interactions and species composition on ecosystem}

\section{functioning}

Consider a set $S=\{1, \ldots, s\}$ of $s$ species $i$ (Figure 1a). An ecosystem is defined as an

This article is protected by copyright. All rights reserved. 
assemblage $A$ of individuals that belong to different species:

$$
A=\{i \in \square S\} .
$$

A cumulative function $F_{\text {observed }}(A)$ such as primary production, respiration or nutrient recycling is observed for each ecosystem $A$. The function $F_{\text {observed }}(\{i\})$ (with $i=1, \ldots, s$ ) for monocultures of each species is also observed.

We set two null hypotheses, named $H_{0}$ and $G_{0}$ respectively (Figure $\mathrm{S} 1$ ). The null hypothesis $H_{0}$ describes a situation where the species interactions within an ecosystem do not affect the ecosystem functioning. Under $H_{0}$, the expected function $F_{\text {expected/HO}}(A)$ of an ecosystem is simply the mean of functions $F_{\text {observed }}(\{i\})$ of all monocultures of co-occurring species $i$ of $A$ (Wilson 1988):

$$
F_{\text {expected } / H_{0}}(A)=\bar{F}_{l \in A} \text { observed }(\{i\})
$$

The null hypothesis $G_{0}$ describes a situation where neither the species interactions nor the species composition affect the ecosystem function. Under $G_{0}$, the expected function $F_{\text {expected/GO}}(A)$ of any ecosystem is consequently constant. By convenience, we assume that the constant is the expected function $F_{\text {expected/Ho }}(S)$ of all the species used in the experiment, i.e., according to the equation 1 , the mean of functions $F_{\text {observed }}(\{i\})$ of all monocultures of species $i$ of $S$ :

This article is protected by copyright. All rights reserved. 


$$
F_{\text {expected } / G_{0}}(A)=F_{\text {expected } / H_{0}}(S)=\bar{F}_{l \in S} \text { observed }(\{i\})
$$

The function $F_{\text {observed }}(A)$ of an ecosystem can then be decomposed as follows:

$$
F_{\text {observed }}(A)=\frac{F_{\text {observed }}(A)}{F_{\text {expected } / H_{0}}(A)} \frac{F_{\text {expected } / H_{0}}(A)}{F_{\text {expected } / G_{0}}(A)} F_{\text {expected } / G_{0}}(A)
$$

or:

$$
F_{\text {observed }}(A)=\alpha(A) \beta(A) F_{\text {expected } / G_{0}}(A)
$$

with:

$$
\alpha(A)=\frac{F_{\text {observed }}(A)}{F_{\text {expected } / H_{0}}(A)}
$$

and:

$$
\beta(A)=\frac{F_{\text {expected } / H_{0}}(A)}{F_{\text {expected } / G_{0}}(A)}
$$

The quotient $\alpha(A)$ corresponds to the effect of species interactions on the ecosystem function. This interaction effect is specific to an ecosystem. It equals to one under $H_{0}$, is lower than one when the species interactions decrease the ecosystem function, and higher than one when the species interactions increase the ecosystem function. The normalized remainder $\beta(A)$ corresponds to the effect of species composition of the ecosystem on its 
function. This composition effect characterizes the subset of species that belong to the ecosystem, relatively to the whole set of species. It equals to one under $G_{0}$, is lower than one when the species composition decreases the ecosystem function, and higher than one when the species composition increases the ecosystem function. The composition effect is one on average when all the possible ecosystems are tested. Finally, the remainder $F_{\text {expected/GO}}(A)$ is by definition constant: this is a scale factor specific to the species set used in the experiment, i.e. the function expected with neither interaction nor composition effects. The scale factor integrates all the variations in species functions in the experiment (e.g., variation in environmental conditions across time). It has the dimension of the ecosystem function. Interaction and composition effects are dimensionless.

\section{Analysing the diversity effects induced by each species on ecosystem functioning}

The idea is now to cluster ecosystems on the basis of the ecosystem interaction and composition effects. We denote by A the set of ecosystems $A$ observed in the experiment. We define $\mathrm{A}_{i}$ (with $i=1, \ldots, s$ ) the cluster of ecosystems $A$ that contains at least one individual of the species $i$ of $S$ :

$$
\mathrm{A}_{i}=\{A \in \text { A such that } \exists i \in \square A\} .
$$

The interaction and composition effects $\alpha\left(\mathrm{A}_{i}\right)$ and $\beta\left(\mathrm{A}_{i}\right)$ induced by each species within the ecosystems are estimated by the mean diversity effects of ecosystems $A$ that contain at least one individual of the species $i$ of $S$, then:

This article is protected by copyright. All rights reserved. 


$$
\alpha\left(A_{i}\right)=\underset{A \in A_{l}}{-\alpha}(A) \text { and } \beta\left(A_{i}\right)=\underset{A \in A_{l}}{-} \beta(A)
$$

\section{Introducing the concept of assembly motif: a simple and operational descriptor of the} composition of an ecosystem

Each ecosystem is a subset of individuals that belong to different species: it can also be described as a subset of individuals that belong to different functional groups of species. We cluster the species set $S=\{1, \ldots, s\}$ into $\sigma$ functional groups $S_{j}$ (with $j=1, \ldots, \sigma$ ) on the basis of their interaction and composition effects $\alpha\left(\mathrm{A}_{i}\right)$ and $\beta\left(\mathrm{A}_{i}\right)$ (Figure 1a). The $\sigma$ functional groups $S_{j}$ allow the assembly of $m=2^{\sigma}-1$ non-empty combinations of functional groups. We term assembly motif $M_{k}$ (with $k=1, \ldots, m$ ) each combination of functional groups, then:

$$
M_{k}=\left\{S_{j} \text { with } j \in\{1, \ldots, \sigma\}\right\} .
$$

We associate each ecosystem $A$ with an assembly motif $M_{k}$ by assuming that each species $i$ of $A$ belongs to a functional group $S_{j}$ of $M_{k}$, and that each functional group $S_{j}$ of $M_{k}$ is represented by at least one individual of species $i$ of $A$. Then, we define $\mathrm{A}_{k}(k=\square 1, \ldots, m)$ as the cluster of ecosystems $A$ described by the assembly motif $M_{k}$ :

$$
\begin{gathered}
\mathrm{A}_{k}=\left\{A \in \text { A such that } \forall i \in \square A, \exists S_{j} \in \square M_{k}\right. \text { with } \\
\left.i \in S_{j} \text {, and } \forall S_{j} \in \square M_{k}, \exists i \in \square A \text { with } i \in S_{j}\right\} .
\end{gathered}
$$

This article is protected by copyright. All rights reserved. 


\section{Modelling the function of an ecosystem according to its assembly motif}

An assembly motif characterizes a particular biotic environment. Next, we cluster ecosystems by assembly motifs, i.e. we cluster ecosystems that share a similar biotic environment (Figure $1 b$ ). We use the ecosystem clustering by assembly motifs to model the ecosystem function. As in equation 6 , we define $\mathrm{A}_{i, k}$ (with $i=1, \ldots, s$ ) the cluster of ecosystems $A$ of $\mathrm{A}_{k}$ that contains at least one individual of the species $i$ of $S$ :

$$
\mathrm{A}_{i, k}=\left\{A \in \mathrm{A}_{k} \text { such that } \exists i \in \square A\right\} .
$$

According to equation 7 , the interaction and composition effects $\alpha\left(\mathrm{A}_{i, k}\right)$ and $\beta\left(\mathrm{A}_{i, k}\right)$ of ecosystems $A$ of clusters $\mathrm{A}_{i, k}$ are estimated by:

$$
\alpha\left(A_{i, k}\right)=\underset{A \in A_{l, k}}{-\alpha}(A) \text { and } \beta\left(A_{i, k}\right)=\underset{A \in A_{l, k}}{-} \beta(A)
$$

According to equations 3 and 8 , the function $F_{\text {modelled }}(A)$ of any ecosystem $A$ is finally modelled as the product of the mean interaction effect, the mean composition effect and the scale factor of ecosystems that contain the same species and share the same assembly motif:

This article is protected by copyright. All rights reserved. 


$$
F_{\text {modelled }}\left(A \in A_{k}\right)=\underset{l \in A}{\alpha}\left(A_{i, k}\right) \bar{\beta}_{l \in A}\left(A_{i, k}\right) F_{\text {expected } / G_{0}}(A) .
$$

\section{Combinatorics and statistics}

The interaction effects $\alpha(A)$ and the composition effects $\beta(A)$ are computed for each ecosystem by using its species composition and the monoculture functions of each species (equations 1 to 5 ). The mean interaction and composition effects $\alpha\left(\mathrm{A}_{i}\right)$ and $\beta\left(\mathrm{A}_{i}\right)$ of the clusters of ecosystems containing a given species $i$ of $S$ are computed by using all the ecosystems containing the species (equation 7). The species centroids are then clustered in functional groups by using Euclidean distance and Ward's linkage algorithm (functions dist, method = "euclidean", and hclust, method = "ward.D" with R, see the scripts in Supporting Information) on the basis of mean diversity effects $\alpha\left(\mathrm{A}_{i}\right)$ and $\beta\left(\mathrm{A}_{i}\right)$ (Legendre \& Legendre 2012).

The hierarchical tree of species centroids clustering is cut at different levels by increasing step-by-step the number of functional groups (see Figure 1). At each step, i.e. for a given number of functional groups, all possible assembly motifs $M_{k}$ are assembled, and the ecosystems are clustered by assembly motifs. For a comparison of different approaches, the species are also clustered by (i) functional groups a priori defined by Tilman et al. (2001), and by (ii) size (i.e. number of species in the ecosystem). In the latter case, each ecosystem size is an assembly motif.

The mean diversity effects $\alpha\left(\mathrm{A}_{i, k}\right)$ and $\beta\left(\mathrm{A}_{i, k}\right)$ of species in each assembly motif are computed according to equation 8 . The function $F_{\text {modelled }}\left(A \in \mathrm{A}_{k}\right)$ is then evaluated according 
to equation 9. The interaction effect is a quotient, and thus measures a multiplicative process: the mean of this biodiversity effect is computed according a geometric formula (equations 7, 8 and 9). The composition effect is a remainder, thus measures an additive process: the mean of this biodiversity effect is computed according an arithmetic formula (equations 1, 2, 7, 8 and 9) (Crawley 2007).

The goodness-of-fit of each clustering model is evaluated by the coefficient of determination $R^{2}$ of the relationship between modelled and observed ecosystem functions, i.e. the ratio between the variance explained by the modelling and the total variance observed in the experiment:

$$
R^{2}=1-\frac{\sum_{A \in A}\left(F_{\text {observed }}(A)-F_{\text {modelled }}(A)\right)^{2}}{\sum_{A \in A}\left(F_{\text {observed }}(A)-\bar{F}_{\text {observed }}(A)\right)^{2}}
$$

The robustness of each clustering model is evaluated by cross-validation. Because of the small number of observations in most experiments, we use a leave-one-out cross-validation, i.e. each ecosystem function is independently predicted by removing the ecosystem to predict from the experiment dataset. The prediction accuracy is evaluated by the model efficiency $E$, i.e. the ratio between the variance explained by the independent predictions and the total variance observed in the experiment (see e.g., Nash \& Sutcliffe 1970):

$$
E=1-\frac{\sum_{A \in A}\left(F_{\text {observed }}(A)-F_{\text {predicted }}(A)\right)^{2}}{\sum_{A \in A}\left(F_{\text {observed }}(A)-\bar{F}_{\text {observed }}(A)\right)^{2}} .
$$

When all the possible ecosystems are observed, all the possible assembly motifs are represented at least once. When only a part of possible ecosystems are observed, some

This article is protected by copyright. All rights reserved. 
assembly motifs are not observed. When an assembly motif is represented by only one ecosystem, the ecosystem function cannot be independently predicted. We define the predicting ratio as the number of ecosystems for which the function can be predicted by the clustering model, divided by the number of all observed ecosystems.

All the computations are done using the R-software (R Development Core Team 2009).

\section{Biodiversity datasets}

We used two datasets to test our approach. The first dataset is based on the observation of all the possible ecosystems assembled with an initial pool of microbial species. Langenheder et al. (2010) designed this experiment to analyse the biodiversity-productivity relationship in bacterial microcosms. They tested all the 63 possible species combinations with a pool of 6 bacteria: $6,15,20,15,6$ and 1 combinations with 1, 2, 3, 4, 5 and 6 bacteria, respectively. Here we analyse the xylose oxidation (ecosystem function) after 48 hours for the 63 bacterial ecosystems, of which 6 are mono-species and 57 pluri-species cultures.

The second dataset is the Cedar Creek Biodiversity II experiment dataset (Tilman et al. 2001). This experiment was dedicated to the analysis of the biodiversity-productivity relationship in grasslands. Here the studied ecosystem function is the yearly plant aboveground biomass per unit area. The experiment contained 88 ecosystems from a pool of 16 prairie species (Tilman et al. 2001; Reich et al. 2012). Diversity treatments consisted of 1, 2, 4, 8 and 16-species plots, each replicated 34 times on average, which corresponds to 168 experimental plots. The species composition in each plot was a random draw from the experimental species pool. All species were grown in monoculture. The 16 prairie species were a priori clustered into 4 functional groups of 4 species: legumes, forbs, C3- and C4grasses. As a case study, here we analyse the aboveground biomass harvested in the 88

This article is protected by copyright. All rights reserved. 
ecosystems in August 2004, of which 35 are mono-species and 53 pluri-species plots. Each biomass is the average value of the harvests of three "unsorted" strips.

\section{Results}

\section{Species clustering based on the diversity effects on ecosystem functioning}

The scale factors $F_{\text {expected/Go }}(A)$ are 0.633 xylose oxidation and $114.8 \mathrm{~g} \mathrm{~m}^{-2}$ of biomass accumulated for a year in the microbial and Biodiversity // experiments, respectively. The decomposition of the function of each ecosystem into dimensionless effects of species interactions $\alpha(A)$ and species composition $\beta(A)$ allows the comparison of these two experiments (Figure 2). The mean interaction effect is $1.46 \pm 0.23$ in the microbial experiment and $2.08 \pm 1.18$ in the Biodiversity // experiment. Even though the interaction effect is significantly correlated with the observed ecosystem function in both experiments, they are more strongly correlated in the Biodiversity // experiment $\left(p<10^{-16}\right)$ than in the microbial experiment $\left(p=3.910^{-6}\right)$ (Figure $2 a$ and $\left.2 b\right)$. The mean composition effect is exactly one $(1.00 \pm 0.27)$ in the microbial experiment where all the species combinations are assembled. The mean composition effect is close to one $(0.97 \pm 0.14)$ in the Biodiversity II experiment: it is not significantly different from one $\left(p<10^{-16}\right)$. In both experiments, the composition effect is significantly correlated with the observed function. However, composition effect and observed function are more strongly correlated in the microbial experiment $\left(p<10^{-16}\right)$ than in the Biodiversity // experiment $(p=0.007)$ (Figure $2 c$ and $\left.2 d\right)$. In both experiments, the interaction effect and the composition effect are not correlated $\left(r_{\text {Pearson }}^{2}\right.$ $=0.019$ and $p=0.305$ in the microbial experiment; $r_{\text {Pearson }}^{2}=1.710^{-4}$ and $p=0.927$ in the Biodiversity /l experiment) (Fig. 3).

This article is protected by copyright. All rights reserved. 
A species-centred analysis can be performed when comparing the location of ecosystems containing a given species on the $\alpha$-by- $\beta$ space (Figure 3 ). Overall, such an analysis highlights tremendous differences between species effects. For instance, in the microbial experiment, SL104 belongs to ecosystems with the highest composition effect on xylose oxidation (Figure 3a). The other species belong to ecosystems that are close to each other's (Figure $3 c$ and S2a). In the Biodiversity // experiment, the functional groups defined by Tilman et al. (2001) are not homogeneous in their effects (Figure $3 b$ and $3 d$ ). Among legumes, Lupinus perennis (Luppe) and Lespedeza capitata (Lesca) belong to ecosystems with the highest interaction effects (Figure 3b), whereas Amorpha canescens (Amocan) belongs to ecosystems with the highest composition effect (Figure $3 d$ and S2b). Finally Petalostemum purpureum (Petpu) belongs to ecosystems characterized by low interaction and composition effects (Figure $3 d$ and $\mathrm{S} 2 b$ ).

The hierarchical clustering (Figure $3 e$ and $3 f$ ) corroborates this explanatory analysis. In the microbial experiment, SL104 is first isolated in a singleton, then SL68 and SL187. Based on a 4-group clustering, the functional groups of species are namely: $\{$ SL104 $\},\{$ SL68 $\}$ and \{ SL187 \} in singletons, then $\{$ SLWC2, SL106, SL197\} (Figure 3e). This means that, when the three species SLWC2, SL106 and SL197 co-occur with each other inside their functional group, and with species SL104, SL68 and SL187 that belong to singletons, they induce similar diversity effects on the ecosystem functioning. In the Biodiversity // experiment, the species are first separated in two groups, then Lupinus perennis is isolated from the smallest group. Based on a 3-group clustering, the functional groups of species are namely: $\{$ Lupinus perennis $\}$ in a singleton, $\{$ Lespedeza capitata, Koeleria cristata, Agropyron smithii, Achillea millefolium, Poa pratensis $\}$ and \{ Amorpha canescens, Liatris aspera, Monarda fistulosa, Andropogon gerardi, Elymus canadensis, Asclepias tuberose, Panicum virgatum, Sorghastrum nutans, Petalostemum purpureum, Schizachyrium scoparium \} (Figure 3f). Ten species belong to the largest group, i.e. a C3-grass, two legumes, three forbs and the four C4-grasses. This clustering means that, when the ten species co-occur with each other

This article is protected by copyright. All rights reserved. 
inside the largest functional group, and with species of other functional groups, they induce similar diversity effects on the ecosystem functioning. Except the C4-grasses, the functional groups a priori defined by Tilman et al. (2001) are split into several clusters: C3-grasses and forbs into two, and the four legumes into three different clusters.

\section{Modelling the ecosystem functioning based on the ecosystem clustering}

Next we focus on the modelling of ecosystem function based on the ecosystem clustering by assembly motifs, i.e. the combination of functional groups of species (see Figure 1). We recall that each species clustering in functional groups is a model, that generates a new set of assembly motifs. Consequently, we explore the model quality, accuracy and efficiency, by increasing step-by-step the number of functional groups (Figure 4). The goodness-of-fit of the model increases from a low value until one when there are as many functional groups as species (Figure $4 a$ and $4 b$ ). The model robustness is evaluated by its efficiency: it also increases, but remains always lower than the goodness-of-fit of the model. In contrary, the predicting ratio decreases with the number of functional groups, from one when all the ecosystems are clustered together in a singleton (all ecosystem functions are predicted by the mean function of all ecosystems), until zero when there are as many functional groups as species (no ecosystem function can be predicted because each ecosystem cluster is a singleton) (Figure $4 c$ and $4 d$ ). The best number of functional groups results from a trade-off between the accuracy $\left(R^{2}\right)$, the efficiency $(E)$ and the predicting ability (predicting ratio) of the model. In the microbial experiment, $R^{2}$ increases from 1 to 5 functional groups (Figure 4a). However, $E$ presents a maximum for 4 clusters of species, which corresponds to a predicting ratio of 53/57 ecosystems (Figure $4 c$ ). In the Biodiversity /I experiment, $R^{2}$ increases, with local maximums for 3, 6 and 8 species functional groups, and the predicting ratio decreases quickly from 1 to 16 functional groups. A species clustering in 3 functional

This article is protected by copyright. All rights reserved. 
groups allows to predict the functions of 52 out of 53 ecosystems.

For a given species clustering, each ecosystem can be described by a unique assembly motif, and its function can be evaluated by modelling (Figure S3-S4 for the independent modelling of both diversity effects). In the microbial experiment, all the 63 species combinations are observed. Species richness is the most frequently used metric of diversity in biodiversity-ecosystem functioning research (Tilman et al. 1997, 2001; Hooper et al. 2005; Langenheder et al. 2010; Reich et al. 2012). As a consequence, here we use species number (ecosystem size) as a reference (Figure $5 a$ and $5 b$ ). This modelling lead to dispersed and overlapping diversity effects (Figure 5a), but goodness-of-fit $\left(R^{2}=0.438\right.$, $\left.p=9.110^{-7}\right)$ and efficiency $\left(E=0.245, p=1.810^{-3}\right)$ are significant (Figure $\left.5 b\right)$. Based on a 4group species clustering, the resulting ecosystem clustering by assembly motifs is much more structured (Figure $5 c$ and $5 d$ ). The diversity effects of ecosystems that share an assembly motif are close to each other, confirming the functional redundancy of clustered species (Figure $5 c$ ). The goodness-of-fit is high $\left(R^{2}=0.892, p<10^{-16}\right)$ and the efficiency of this modelling remains high and highly significant $\left(E=0.828, \mathrm{p}<10^{-16}\right)$ (Figure $5 d$ ).

In the Biodiversity // experiment, only 53 out of 65519 (65535-16 monocultures) plurispecies ecosystems are observed, thus less than $0.1 \%$ of all possible species assemblages. The clustering of ecosystems by their size induces dispersed and overlapping ecosystem groups (Figure 6a), a poor goodness-of-fit $\left(R^{2}=0.489, p=1.210^{-9}\right)$ and a poor efficiency $\left(E=0.142, \mathrm{p}=1.210^{-3}\right)$ of the modelling (Figure $6 b$ ). A 4-group clustering based on functional groups a priori defined by Tilman et al. (2001) improves significantly the goodness-of-fit $\left(R^{2}=0.771, \mathrm{p}=4.410^{-16}\right)$, but more weakly the efficiency of the modelling $\left(E=0.375, p=2.710^{-8}\right)$, and the predicting ratio equals to $46 / 53$ (Figure $6 c$ and $6 d$ ). An $a$ posteriori species clustering in only 3 groups improves strongly both the goodness-of-fit $\left(R^{2}=0.863, \mathrm{p}<10^{-16}\right)$ and the efficiency $\left(E=0.717, \mathrm{p}=2.210^{-14}\right)$ of the modelling (Figure 
$6 e$ and $6 f)$. Moreover, the function of $52 / 53$ ecosystems can be predicted independently.

\section{Discussion}

\section{Separating the interaction and composition effects: an alternative proposal}

The decomposition of ecosystem functions into diversity effects has been successfully used in the past to analyse biodiversity-ecosystem functioning experiments (Loreau \& Hector 2001; Reich et al. 2012). This method follows an integrative path by computing the covariance between the observed and expected contributions of each species to ecosystem functioning. We here followed the same philosophy but used the ratio between observed and expected yield (so-called "relative yield of the mixture", RYM) instead of the covariance, as suggested by Wilson (1988). Based on this decomposition, we defined two new elementary ecosystem-level diversity effects: interaction and composition effects. Both interaction and composition effects are dimensionless, which allows comparisons between experiments performed in various conditions.

The two experiments that we re-analyse here are very different: bacterial assemblages grown for 48 hours in laboratory (Langenheder et al. 2010) and grassland mixtures cultivated for several years in the field (Tilman et al. 2001). In the microbial experiment, the observed function is strongly correlated to the composition effect. In both experiments, species interactions greatly increase ecosystem function, between 1.4 and 2.1 times, indicating strong complementary interactions (e.g., facilitation, niche differentiation) between species, as suggested by Tilman et al. (2001) and Langenheder et al. (2010). In addition, we found that the covariance between the interaction and composition effects is not significantly different from zero, which corroborates Loreau \& Hector (2001)'s results. These findings

This article is protected by copyright. All rights reserved. 
demonstrate that the interaction and composition effects are independent in both experiments, but the two diversity effects contribute significantly to ecosystem functioning.

\section{The emerging concept of assembly motifs}

We propose to quantify the net effect of species interactions on ecosystem functioning through the lens of assembly motifs, i.e. a combination of co-occurring functional groups within an ecosystem. An assembly motif is a pattern of species composition that reflects a given biotic environment. Our results show that ecosystems described by the same assembly motif display diversity effects on ecosystem functioning similar to each other in terms of interaction and composition effects. An assembly motif therefore describes the biotic environment that regulates the effects of species interactions on a given ecosystem function.

The underlying condition of our modelling framework is that the presence/absence of at least one species from each functional group changes the ecosystem-wide species effect in a similar way (Jaillard et al. 2014). This condition is the simplest and the most commonly used in ecology (Diaz \& Cabido 2001; Hooper et al. 2005). It implicitly assumes that the presence of particular species, thus of particular interactions, is more important than the number of interactions, the number of species or the number of functional groups. Some authors have long pointed out that the composition of an ecosystem, i.e. the identity of species or functional groups, affects its functioning more than diversity per se (Hooper \& Vitousek 1997). Our results confirm the validity of this hypothesis in both studied experiments.

Our modelling framework is based on combinatorics through combinations and clustering of species, functional groups and ecosystems. Clustering of species or ecosystems is a simplification of the real world. It assumes that clustered species are functionally redundant,

This article is protected by copyright. All rights reserved. 
which means in our case that they induce roughly the same effects on the ecosystem functioning. However, the functional redundancy, and thus the species clustering, is specific to the considered experiment, to the set of species used and to the ecosystem function observed in the experiment (Loreau 2004). Species clustering is only a shortcut that should enable a better understanding of reality. The clustering of species based on their diversity effects reduces the range of possibilities to affect the ecosystem functioning. The clustering of ecosystems by assembly motifs reduces the range of effects induced by the species interactions and composition on ecosystem functioning. The variance within each ecosystem cluster is low. The clustering thus enables the a posteriori determination of a likely interacting schema based on parsimonious species clusters and readable ecosystem clusters. It finally sets up a comprehensive interacting organization of species within ecosystems, without any a priori knowledge of species properties.

\section{Identifying and quantifying the interacting roles of species within ecosystems}

We clearly showed that an ecosystem clustering based on assembly motifs is much more suitable than the classical clustering based on the ecosystem size, such as the number of species or functional groups. Langenheder et al. (2010) biologically showed that the species SL104 plays a key role on xylose oxidation. Our modelling approach retrieves this key role of SL104, and specifies that the species increases the ecosystem function by composition effect rather than interaction effect. It also shows that the three species SLWC2, SL106 and SL197 are clustered in a same functional group, thus they induce similar diversity effects by interacting between them and with others.

In the Biodiversity // experiment, we highlight that only three a posteriori functional effect groups explain and successfully predict ecosystem functioning. The a priori species clustering based on the number of species as well as the clustering defined by Tilman et al.

This article is protected by copyright. All rights reserved. 
(2001) are both based on four groups: they explain and predict less accurately the ecosystem biomass than our a posteriori approach. Our a posteriori approach is thus more accurate, more efficient and more parsimonious than both a priori approaches based on ecosystem size and functional groups a priori defined. Surprisingly the four legumes classically clustered into a single functional group (legume) were found in different functional groups based on our a posteriori clustering. Lupinus perennis belongs to the ecosystem cluster with the highest interaction effects. Lupinus perennis is a legume, the leaves and fine roots of which have a very short longevity, lesser than 4 weeks, releasing large amounts of nitrogen in soil (Craine et al. 2002). In Europe, the Lupinus genus is also known among legumes to produce cluster roots that release citrate and protons and mobilize poorly available nutrients such as phosphorus (Hinsinger et al. 2002; Jaillard et al. 2003; Lambers et al. 2013). The Lupinus species from the New World are less studied but Lambers et al. (2012) reported that Lupinus lepidus also produces cluster-like roots. Lespedeza capitata is clustered with a forb (Achillea millefolium) and three C3-grasses (Koeleria cristata, Agropyron smithii and Poa pratensis). The species cluster has high interaction effects but low composition effects. Note that Lupinus perennis and Lespedeza capitata are always isolated in small functional groups and have strong structuring effects on the ecosystem function across years (from 2001 to 2007, data not shown). Amorpha canescens belongs to ecosystems with the highest composition effects but low interaction effects. Our results confirm that legumes play a key role in ecosystem-level biomass production, as previously highlighted by many authors (e.g., Tilman et al. 1997, 2001), but, as suggested by Craine et al. (2002) and Wright et al. (2006), they also indicate that the 'legume' functional group is not homogeneous in the ability of legumes to affect plant biomass.

This article is protected by copyright. All rights reserved. 


\section{Biodiversity effects: a new conceptual framework}

The approach developed here first separates the interaction effect from the composition effect of diversity on an ecosystem function, then clusters species in functional groups on the basis of these diversity effects on ecosystem functioning. However, the novelty is mainly to combine functional groups of species and to assume that any species assemblage, matching to all possible combinations of functional groups, i.e. all possible assembly motifs can significantly affect, positively or negatively, the interaction and composition effects. Jaillard et al. (2014) already showed that a combinatorial approach makes it possible to reproduce all shapes of diversity-ecosystem functioning relationships reported in the experimental literature, suggesting that the multi-faceted response of ecosystems to biodiversity changes is driven by effects of assembly probabilities and variations in species properties. We here demonstrate that a combinatorial approach also allows the modelling of ecosystem functioning without any hypothesis about its biotic or environmental determinants, and without any information on species functional traits. We only use the available experimental data, i.e. the function and species composition of ecosystems, and the function of species in monoculture. Wright et al.'s (2006) study is the only one to assess random species clustering based on their ability to predict an ecosystem function. The main result obtained by Wright et al. (2006) was that the explanatory powers of a priori and random clustering were not significantly different. In contrast to the conclusion of Wright et al. (2006), our results show that an a posteriori species clustering can be highly explanatory. It even makes it possible to predict with accuracy the functioning of an ecosystem on the sole basis of its species composition.

A posteriori approaches such as ours aim at describing the structure of raw data. In our case, the idea is to determine the functional structure of ecosystems that best accounts for the observed data without attempting to explain the underlying biological processes. This approach allows testing some hypotheses, in particular it allowed us to challenge the

This article is protected by copyright. All rights reserved. 
widespread use of the legume-forb-graminoid clustering when investigating the role of biodiversity in regulating ecosystem functioning. It also makes it possible to efficiently predict a given ecosystem function based on a set of ecosystems in which species composition and function have already been observed. Nevertheless, a posteriori approaches remain statistical, phenomenological, and correlative. They should be complemented by a priori approaches that formulate new explanatory hypotheses based on the findings of a posteriori approaches. For instance, the identification of functional traits associated to different species groups identified by our combinatorial approach could help to reveal the underlying biological processes. Ultimately, a deeper understanding of biodiversity-ecosystem functioning relationships should ideally come from a combination of a posteriori and a priori approaches: the former to explore data and reveal real patterns, the latter to determine the functional traits or biological processes responsible for the observed species patterns. This combination is best suited to providing robust, general, explanatory and anticipatory predictions of the effects of species diversity on ecosystem functioning (Mouquet et al. 2015).

\section{Conclusion}

We propose a combinatorial model to quantify the net effects of species interactions on ecosystem functioning and an efficient method to fit species clustering to experimental datasets. When applied to two datasets, a microbial experiment and the Biodiversity II experiment, we show that assembly motifs, i.e. patterns of ecosystem assembly that reflect patterns of species interactions, explain a large part of the biodiversity effects on ecosystem functioning. This confirms that the existence of interactions of a certain type is more important than the number of interactions, of species or of functional groups. Our model is based solely on assembly motifs defined as patterns of ecosystem functional structure: it is the first model that characterizes species by their ability to affect ecosystem functioning,

This article is protected by copyright. All rights reserved. 
without explicitly accounting for their biological properties (e.g., functional traits).

\section{Acknowledgements}

The authors gratefully thank Dr Silke Langenheder and the University of Minnesota for having put at their disposal the datasets discussed in this paper. They also thank Dr Alain Rapaport for his helpful contribution to mathematical formulations. This work was funded by the project Effet d'échantillonnage sur la compréhension et la prédiction du fonctionnement des écosystèmes (INRA). ML was supported by the TULIP Laboratory of Excellence (ANR10-LABX-41). CV was supported by the French Foundation for Research on Biodiversity (FRB; www.fondationbiodiversite.fr) in the context of the CESAB project "Assembling, analysing and sharing data on plant functional diversity to understand the effects of biodiversity on ecosystem functioning: a case study with French Permanent Grasslands" (DIVGRASS), by a Marie Curie International Outgoing Fellowship within the $7^{\text {th }}$ European Community Framework Program (DiversiTraits project, no. 221060) and by the European Research Council (ERC) Starting Grant Project "Ecophysiological and biophysical constraints on domestication in crop plants" (Grant ERC-StG-2014-639706CONSTRAINTS).

\section{Data accessibility}

The $R$ scripts and datasets can be found at datadryad.com, https://doi.org/10.5061/dryad.rh4v0 (Jaillard, Richon, Deleporte, Loreau \& Violle, 2017)

This article is protected by copyright. All rights reserved. 


\section{Authors's contributions}

B.J. conceived the research; B.J. and C.R. implemented the code; B.J. and P.D. developed the statistics; B.J., C.R., M.L. and C.V. drew the figures and wrote the manuscript.

\section{References}

Balvanera, P., Pfisterer, A.B., Buchmann, N., He, J.S., Nakashizuka, T., Raffaelli, D. \& Schmid, B. (2006). Quantifying the evidence for biodiversity effects on ecosystem functioning and services. Ecology Letters, 9, 1146-1156.

Craine, J.M., Tilman, D., Wedin, D., Reich, P., Tjoelker, M. \& Knops, J. (2002). Functional traits, productivity and effects on nitrogen cycling of 33 grasslands species. Functional Ecology, 16, 653-574.

Crawley, M.J. (2007). The R Book. John Wiley \& Sons, Ltd, pp. 942.

Díaz, S. \& Cabido, M. (2001). Vive la différence: plant functional diversity matters to ecosystem processes. Trends in Ecology and Evolution, 16, 646-655.

Duffy, J. E. (2009). Why biodiversity is important to the functioning of real-world ecosystems. Frontiers in Ecology and the Environment, 7, 437-444.

Garnier, E., Navas, M.L., Austin, M.P., Lilley, J.M. \& Gifford, R.M. (1997). A problem for biodiversity-productivity studies: how to compare the productivity of multispecific plant mixtures to that of monocultures? Acta Oecologica, 18, 657-670.

McGill, B., Enquist, B.J., Weiher, E. \& Westoby, M. (2006). Rebuilding community ecology from functional traits. Ecology Letters, 21, 178-185.

Grace, J. 1990. On the relationship between plant traits and competitive ability. In: Perspectives on plant competition (eds Grace, J. \& Tilman, D.). Academic Press, San

This article is protected by copyright. All rights reserved. 
Diego, U.S.A., pp. 51-65.

Hinsinger, P., Plassard, C., Tang, C. \& Jaillard, B. (2002). Origins of root-mediated pH changes in the rhizosphere and their responses to environmental constraints: a review. Plant and Soil, 248, 43-59.

Hooper, D. U., Chapin, F. S., Ewel, J. J., Hector, A., Inchausti, P., Lavorel, S., Lawton, J. H., Lodge, D. M., Loreau, M., Naeem, S., Schmid, B., Setälä, H., Symstad, A. J., Vandermeer, J., \& Wardle, D. A. (2005). Effect of biodiversity on ecosystem functioning: a consensus of current knowledge. Ecological Monographs, 75, 3-35.

Hooper, D. U. \& Vitousek, P. M. (1997). The Effects of Plant Composition and Diversity on Ecosystem Processes. Science, 277, 1302-1305.

Huston, M. A. (1997). Hidden treatments in ecological experiments: re-evaluating the ecosystem function of biodiversity. Oecologia, 111, 449-460.

Jaillard, B., Plassard, C. \& Hinsinger, P. (2003). Measurements of $\mathrm{H}^{+}$fluxes and concentrations in the rhizosphere. In : Handbook of Soil Acidity, éd par Rengel, Z., Marcel Dekker Inc, New York, pp 231-266.

Jaillard, B., Rapaport, A., Harmand, J., Brauman, A. \& Nunan, N. (2014). Community assembly effects shape the biodiversity-ecosystem functioning relationships. Functional Ecology, 28, 1523-1533.

Jiang, L., Wan, S. \& Li, L. (2009). Species diversity and productivity: why do results of diversity-manipulation experiments differ from natural patterns? Journal of Ecology, 97, 603-608.

Kirwan, L., Connolly, J., Finn, J.A., Brophy, C., Lüscher, A., Nyfeler, D., \& Sebastià, M.-T. (2009). Diversity-interaction modeling: estimating contributions of species identities and interaction to ecosystem function. Ecology, 90, 2032-2038.

Lambers, H., Bishop, J. G., Hopper, S. D., Laliberté, E. \& Zúñiga-Feest, A. (2012). Phosphorus-mobilisation ecosystem engineering: The roles of cluster roots and carboxylate exudation in young P-limited ecosystems. Annals of Botany, 110, 329-348.

Lambers, H., Clements, J. C. \& Nelson, M. N. (2013). How a phosphorus-acquisition

This article is protected by copyright. All rights reserved. 
strategy based on carboxylate exudation powers the success and agronomic potential of lupines (Lupinus, Fabaceae). American Journal of Botany, 100, 263-288.

Langenheder, S., Bulling, M. T., Solan, M. \& Prosser, J. I. (2010). Bacterial BiodiversityEcosystem functioning Relations Are Modified by Environmental Complexity. PLoS ONE, 5, e10834. doi:10.1371/journal.pone.0010834.

Lavorel, S. \& Garnier, E. (2002). Predicting changes in community composition and ecosystem functioning from plant traits: revisiting the Holy Grail. Functional Ecology, $16,545-556$.

Legendre, P. \& Legendre, L. (2012). Numerical Ecology. Third edition, eds Elsevier, pp 990.

Loreau, M. (2004). Does functional redundancy exits? Oikos, 104, 606-611.

Loreau, M. \& Hector, A. (2001). Partitioning selection and complementarity in biodiversity experiments. Nature, 412, 72-76.

Loreau, M., Naeem, S., Inchausti, P., Bengtsson, J., Grime, J. P., Hector, A., Hooper, D. U., Huston, M. A., Raffaelli, D., Schmid, B., Tilman, D. \& Wardle, D. A. (2001). Biodiversity and ecosystem functioning: current knowledge and future challenges. Science, 294, 804-808.

Milo, R., Shen-Orr, S., Itzkovitz, S., Kashtan, N., Chklovskii, D. \& Alon U. (2002). Network Motifs: Simple Building Blocks of Complex Networks. Science, 298, 824-827.

Nash, J. E. \& Sutcliffe, J. V. (1970). River Flow Forecasting through Conceptual Models Part I-A Discussion of Principles, Journal of Hydrology, 10, 282-290.

R Development Core Team (2009) R: A Language and Environment for Statistical Computing. R Foundation for Statistical Computing, Vienna, Austria. ISBN 3-90005107-0, URL http://www.R-project.org

Reich, P. B., Tilman, D., Isbell, F., Mueller, K., Hobbie, S. E., Flynn, D. F. B. \& Eisenhauer, N. (2012). Impacts of Biodiversity Loss Escalate Through Time as Redundancy Fades. Science, 336, 589-592.

Tilman, D., Knops, J., Wedin, D., Reich, P., Ritchie, M. \& Siemann, E. (1997). The influence of functional diversity and composition on ecosystem processes. Science, 277, 1300-

This article is protected by copyright. All rights reserved. 
1302.

Tilman, D., Knops, J., Wedin, D., Reich, P., Ritchie, M. \& Siemann, E. (2001). Diversity and productivity in a long-term grassland experiment. Science, 294, 843-846.

Violle, C., Reich, P.B., Pacala, S.W., Enquist, B.J. \& Kattge, J. (2014). The emergence and promise of functional biogeography. Proceedings of the National Academy of Sciences of the USA, 111, 13690-13696.

Wilson, J. B. (1988). Shoot competition and root competition. Journal of Applied Ecology, 25, 279-296.

Wright, J. P., Naeem, N., Hector, A., Lehman, C., Reich, P. B., Schmid, B. \& Tilman, D. (2006). Conventional functional classification schemes underestimate the relationship with ecosystem functioning. Ecology Letters, 9,111-120.

\section{Figure legends}

Figure 1: Step-by-step clustering framework to model the diversity effects on an ecosystem function. (a) An ecosystem $A$ is defined as a set of co-occurring species and is characterized by an aggregate function $F$. Species are clustered into functional groups (here $\sigma=3$ for instance) on the basis of the mean diversity effects of clusters of ecosystems containing a given species. (b) Each ecosystem is then described by a combination of functional groups, i.e. an assembly motif $M_{k}$ (here $m=2^{\sigma}-1=7$ possible assembly motifs). Ecosystems described by the same assembly motif $M_{k}$ are grouped into the clusters $\mathrm{A}_{k}$ and characterized by the aggregate functions $F\left(\mathrm{~A}_{k}\right)(k=1 \ldots 7)$. The goodness-of-fit of the model clustering is evaluated by its determination coefficient and its robustness by cross validation.

This article is protected by copyright. All rights reserved. 
Figure 2: Effects of species interactions and species composition of an ecosystem function.(a) and (b) Interaction effect vs ecosystem function, (c) and (d) Composition effect vs ecosystem function. The coefficient of correlation $r_{\text {Pearson }}^{2}$ of the relationship are indicated: they are significant at $p<0.001$.

Figure 3: Species clustering based on the mean diversity effects of the clusters of ecosystems containing a given species. (a) and (b) Interaction effect vs composition effect. Example of a cluster of ecosystems containing a given species (SL104 or Lupinus perennis). (c) and (d) Interaction effect vs composition effect. Centroids of the clusters of ecosystems containing each species. $(e)$ and $(f)$ Trees of hierarchical clustering of centroids of the ecosystem clusters containing each species. The centroids are clustered by using Euclidean distance and Ward's linkage algorithm. In $(d)$ and $(f)$, different colours correspond to different functional groups defined by Tilman et al. (2001), legumes (blue), C3-grasses (red), C4-grasses (green) and forbs (gold).

Figure 4: Accuracy, efficiency and predicting ability of modelling versus the number of functional groups. (a) and (b) Coefficient of determination $R^{2}$ (in black) and efficiency $E$ (in red) of the relationship between the ecosystem function observed vs modelled $\left(R^{2}\right)$ or predicted $(E)$ by cross validation. $(c)$ and $(d)$ Predicting ratios, i.e. the proportion of ecosystems of which the function can be predicted by the clustering model.

Figure 5: Ecosystem clustering, goodness-of-fit and efficiency of the clustering model for ecosystem functioning in the microbial experiment (Langenheder et al. 2010). (a) and (b) Modelling based on the ecosystem size (number of species). (c) and (d) Modelling based on an a posteriori 4-group species clustering. (a) and (c) Interaction effect vs 
composition effect. (b) and (d) Relationship between modelled and observed ecosystem functions. Each bar corresponds to the error induced by leaving out the ecosystem to predict. Different coloured symbols correspond to different assembly motifs. Solid black line is the $1: 1$ line.

Figure 6: Ecosystem clustering, goodness-of-fit and efficiency of the clustering model for ecosystem functioning in the Biodiversity II experiment (Tilman et al. 2001). (a) and (b) Modelling based on the ecosystem size (number of species). (c) and (d) Modelling based on an a priori 4-group species clustering defined by Tilman et al. (2001), i.e. legumes, forbs, C3- and C4-grasses. (c) and (d) Modelling based on an a posteriori 3-group species clustering. (a), (c) and (e) Interaction effect vs composition effect. (b), (d) and ( $f$ ) Relationship between modelled and observed ecosystem functions. Each bar corresponds to the error induced by leaving out the ecosystem to predict. Different coloured symbols correspond to different assembly motifs. Solid black line is the $1: 1$ line.

This article is protected by copyright. All rights reserved. 


\section{Supporting Information}

Figure S1: Decomposition of ecosystem function in interaction and composition effects. The function $F_{\text {observed }}(A)$ of an ecosystem $A$ is decomposed by referring to two null hypotheses $H_{0}$ and $G_{0}: H_{0}$ assumes that the species interactions have no effect on ecosystem functioning, and $G_{0}$ assumes that neither the species interactions nor the species composition have effect on ecosystem functioning. The two null models are computed using the functions of species in monoculture, that belong to the ecosystem $A$ for $H_{0}$, that belong to the ecosystem $A$ and the whole experimental pool $S$ for $G_{0}$. The modelling allows to define an interaction effect $\alpha(A)$ and a composition effect $\beta(A)$. Here, $S=\{1,2,3\}$ and $A=\{2$, $3\}$.

Figure S2: Species centroids of the clusters of ecosystems containing a given species in the interaction effect $x$ composition effect space. The figures correspond to Figure $3 b$ and $3 c$ enlarged and focused on the species centroids. The centroids are clustered by using Euclidean distance and Ward's linkage algorithm. In (b), different colours correspond to different functional groups defined by Tilman et al. (2001), legumes (blue), C3grasses (red), C4-grasses (green) and forbs (gold).

Figure S3: Goodness-of-fit and efficiency of the clustering model for diversity effects in the microbial experiment (Langenheder et al. 2010). (a) and (b) Modelling based on the ecosystem size (number of species). (c) and (d) Modelling based on an a posteriori 4group species clustering. (a) and (c) Interaction effect. (b) and (d) Composition effect. Each bar corresponds to the error induced by leaving out the ecosystem to predict. Different 
coloured symbols correspond to different assembly motifs. Solid black line is the 1:1 line.

Figure S4: Ecosystem clustering, goodness-of-fit and efficiency of the clustering model for diversity effects in the Biodiversity II experiment (Tilman et al. 2001). (a) and (b) Modelling based on the ecosystem size (number of species). (c) and ( $d$ ) Modelling based on an a priori 4-group species clustering defined by Tilman et al. (2001), i.e. legumes, forbs, C3- and C4-grasses. (a), (c) and (e) Interaction effect. (b), (d) and ( $f$ ) Composition effect. Each bar corresponds to the error induced by leaving out the ecosystem to predict. Different coloured symbols correspond to different assembly motifs. Solid black line is the 1:1 line.

This article is protected by copyright. All rights reserved. 
a. Clustering of species

Original set of species

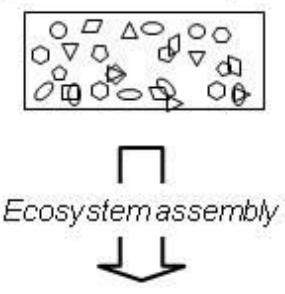

Ecosystems b. Clustering of ecosystems

Functional groups of species

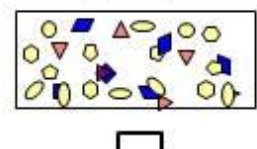

Each ecosystemis considered as a combination of functional groups, i.e. an assembly motif $+5$

Ecosystems

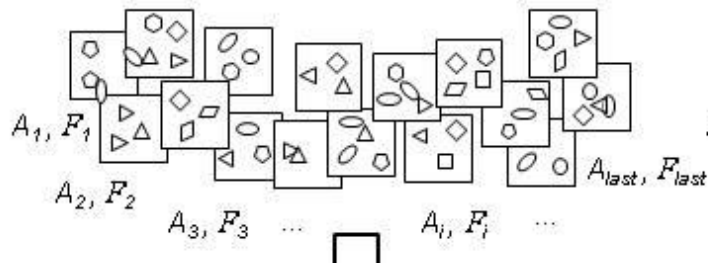

Clustering of species based on diversity effects $+5$

Functional groups of species

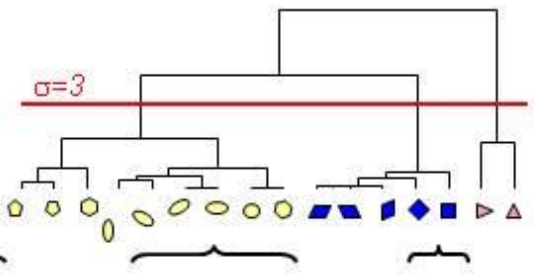

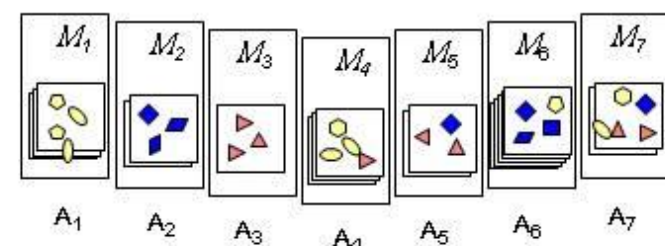

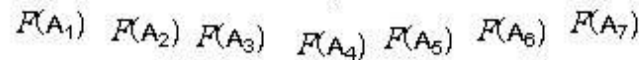

Figure 1

This article is protected by copyright. All rights reserved. 
(a) Microbialexperiment

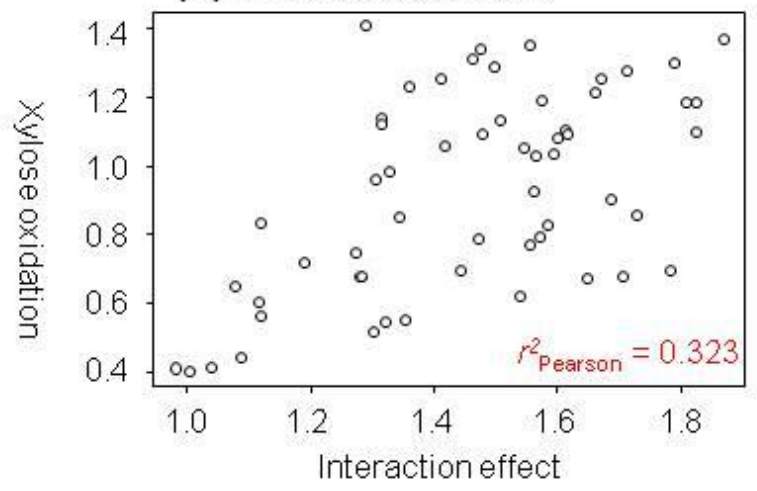

(c) Microbialexperiment

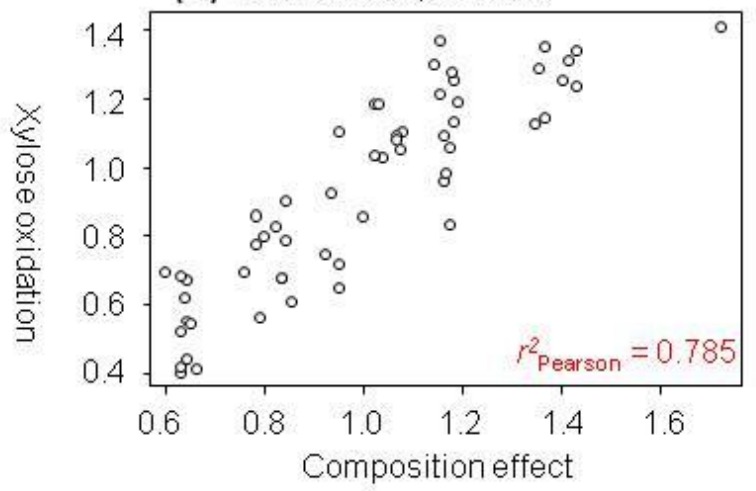

(b) Biodiversity // experiment

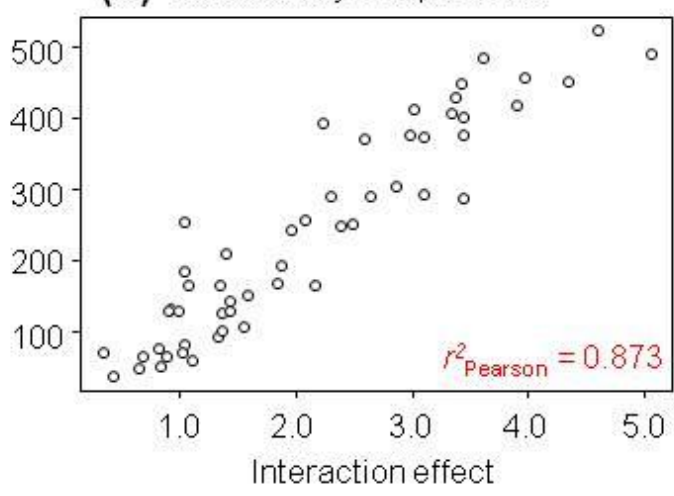

(d) Biodiversity /lexperiment

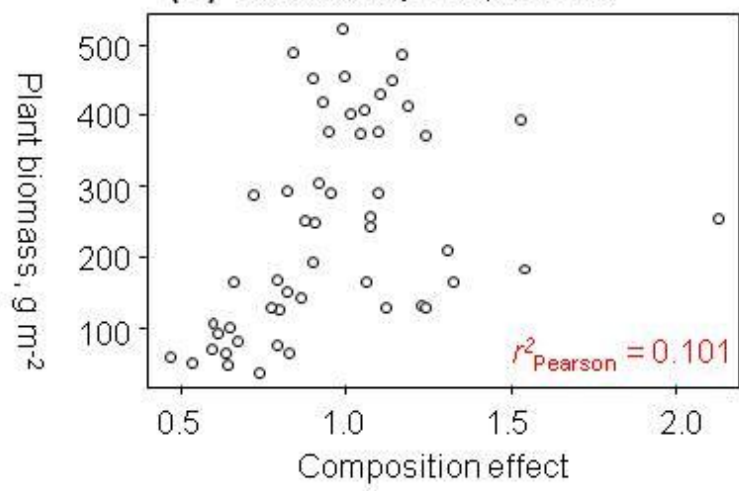

Fig. 2

This article is protected by copyright. All rights reserved. 
(a) Microbialexperiment

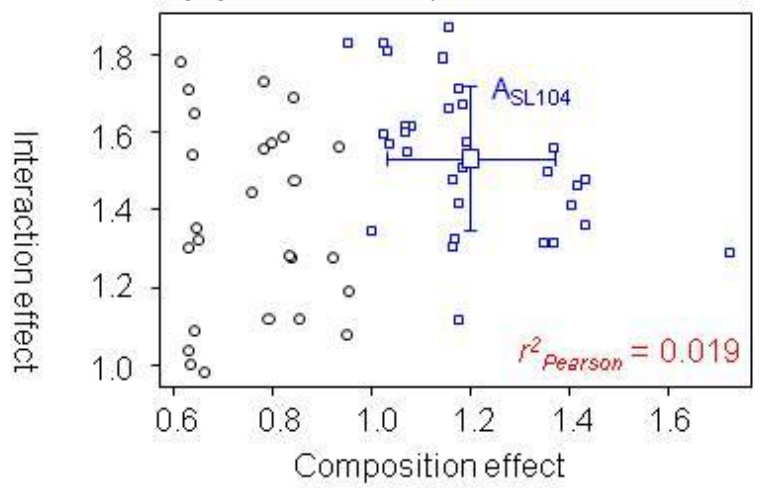

(c) Microbialexperiment
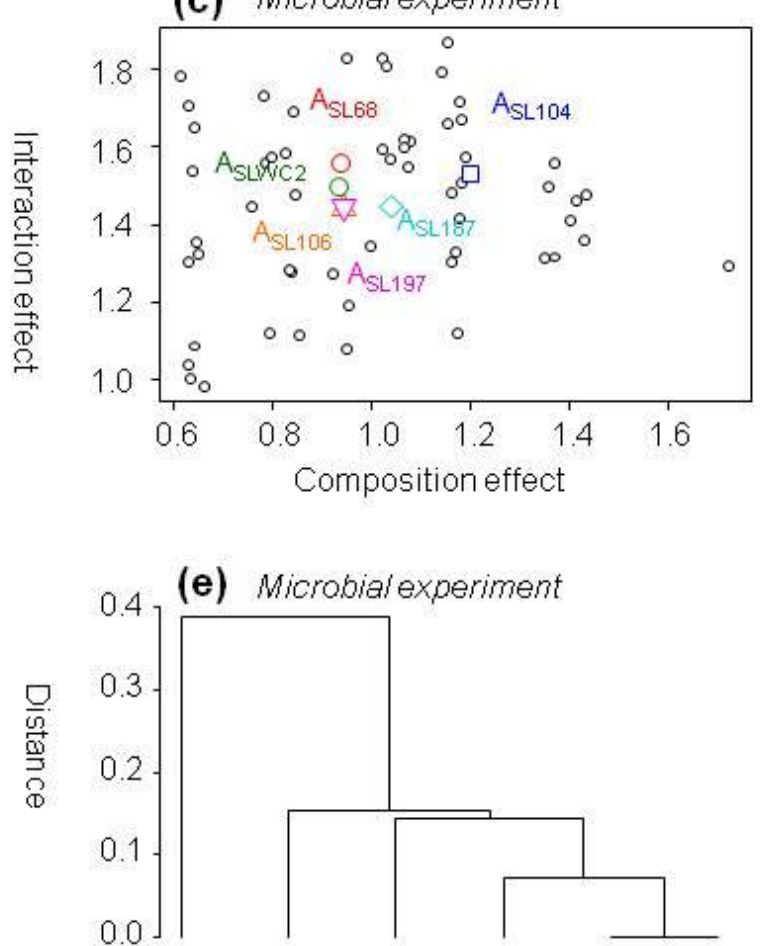

(b) Biodiversity // experiment

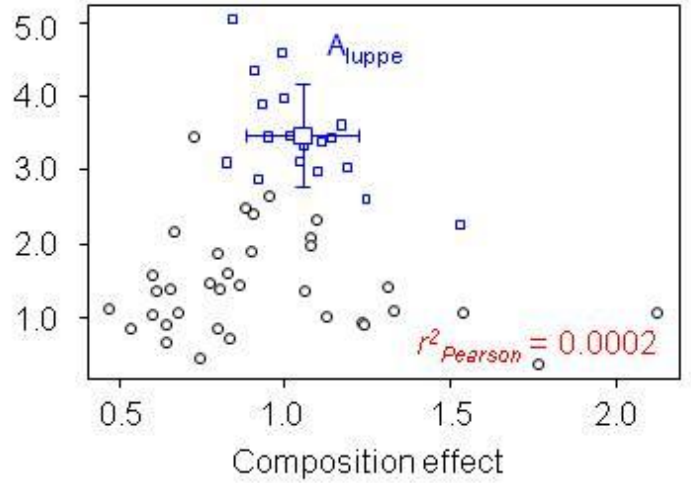

(d) Biodiversity // experiment

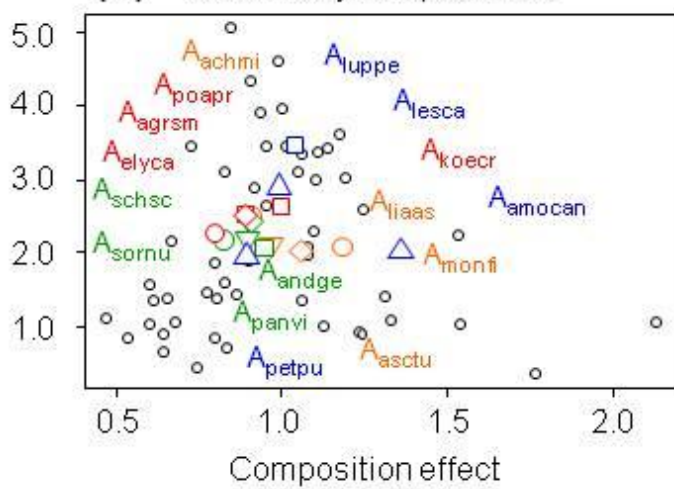

(f) Biodiversity //experiment

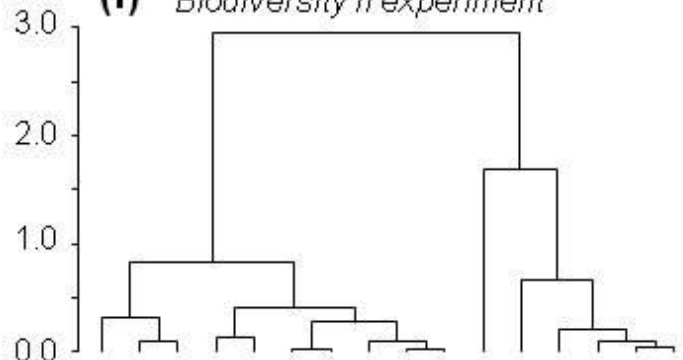

Centroids of ecosystems containing a species 


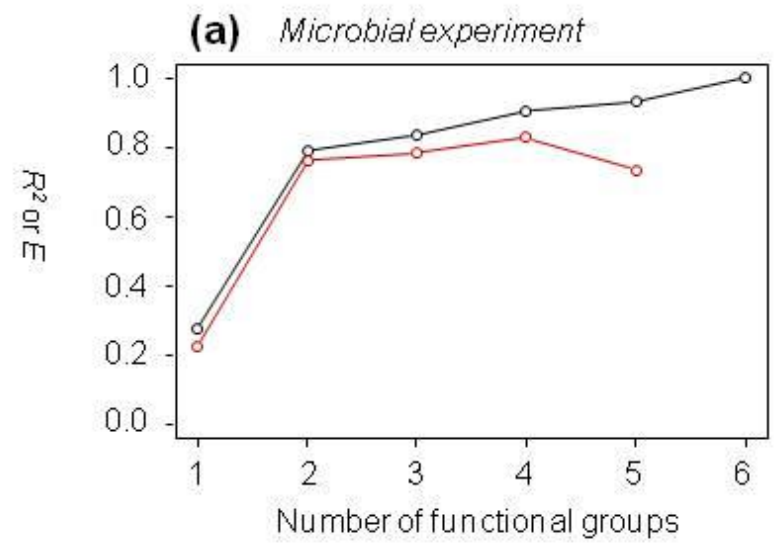

(b) Biodiversity //experiment

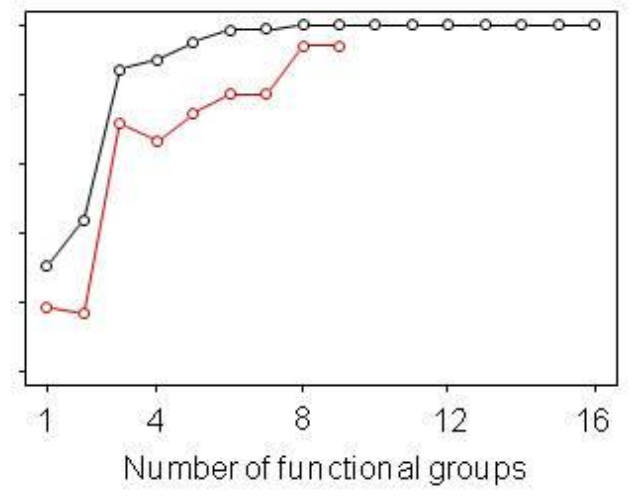

(c) Microbialexperiment

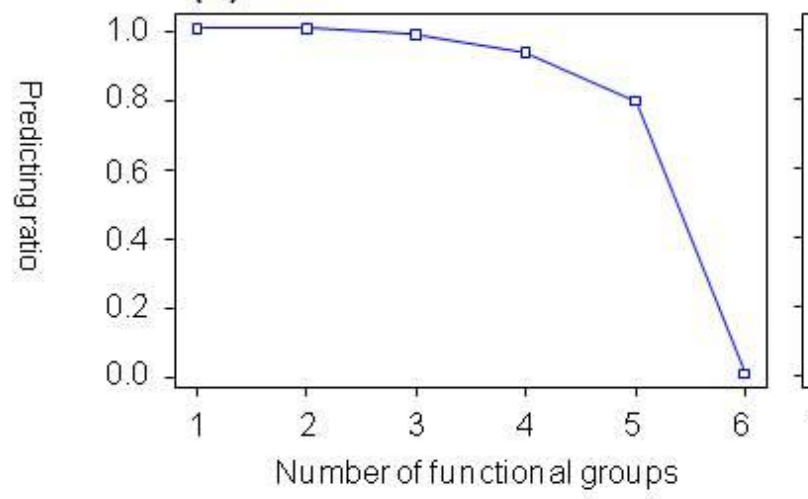

(d) Biodiversity /lexperiment

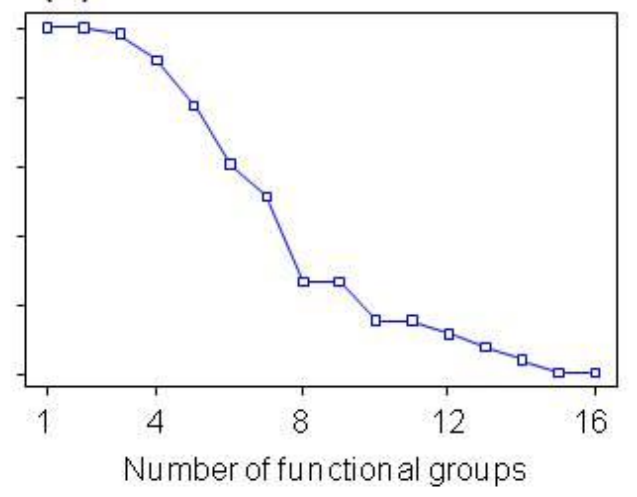

Fig. 4

This article is protected by copyright. All rights reserved.

Jaillard, B., Richon, C., Deleporte, P., Loreau, M., Violle, C. (2018). An a posteriori species 
Modelling outcome of an a priori clustering based on the ecosystem size (number of species)

(a)

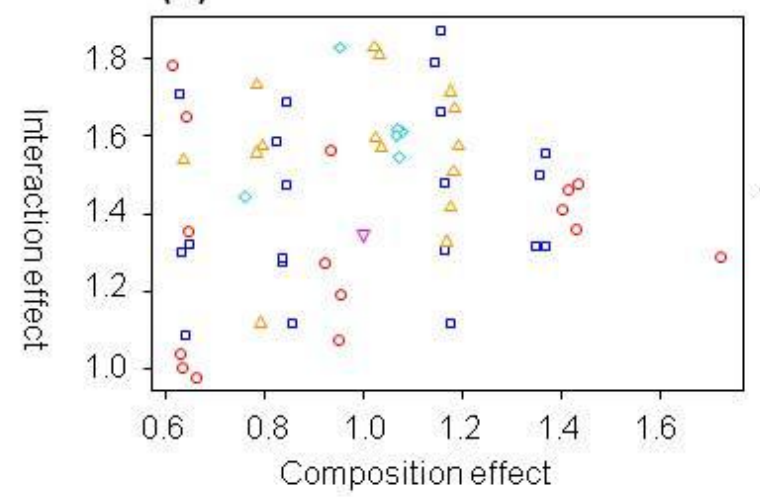

(b)

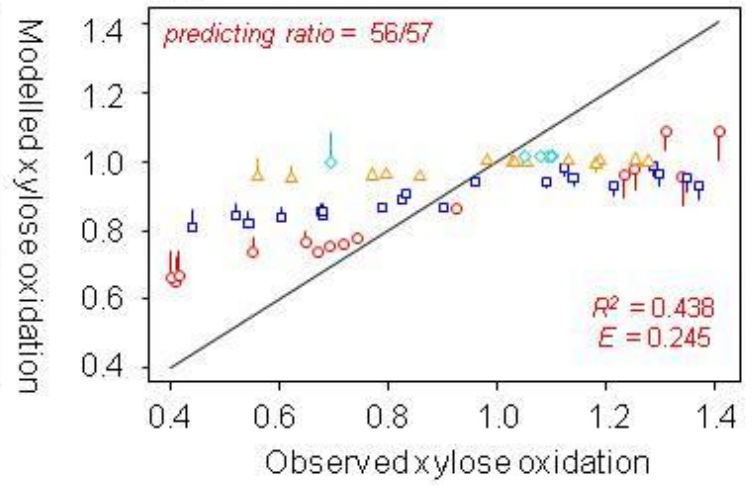

Modelling outcome of an a posteriori 4-group clustering of species

(c)

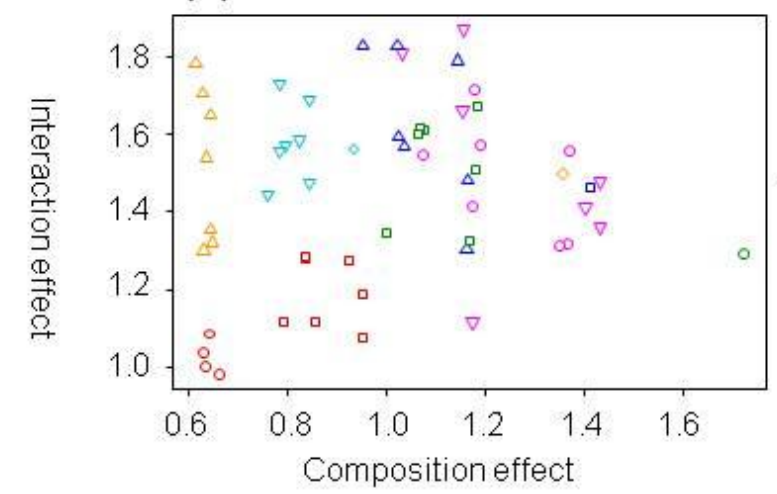

(d)

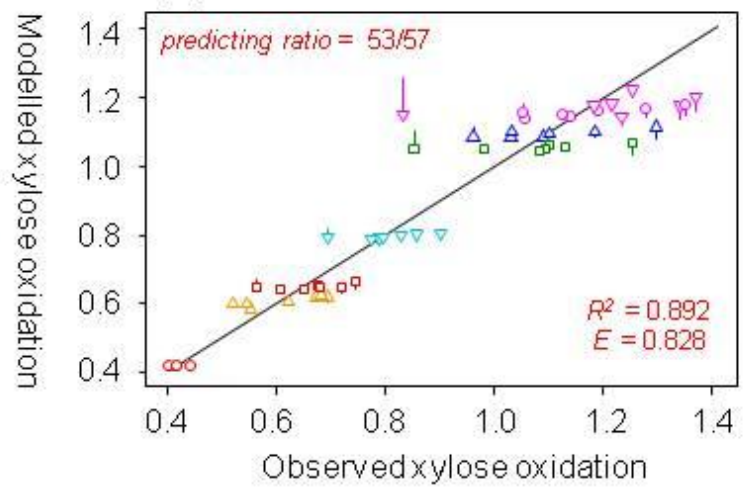

Fig. 5

This article is protected by copyright All rights reserved. 
Modelling outcome of an a priori clustering based on the ecosystem size (number of species)

(a)

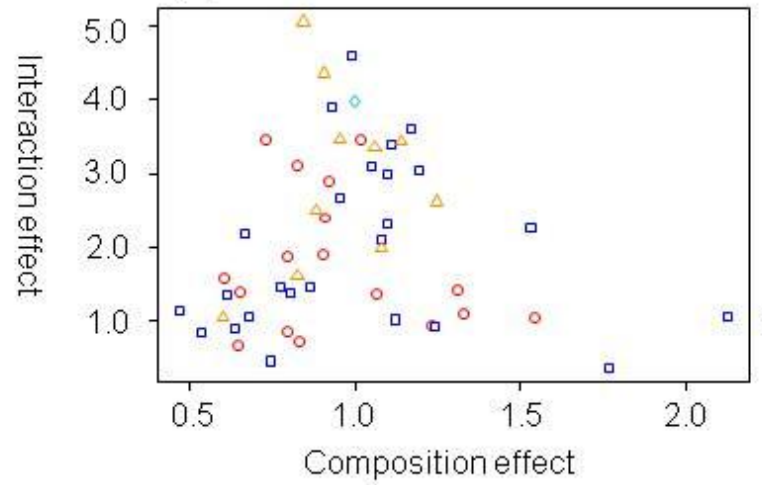

(b)

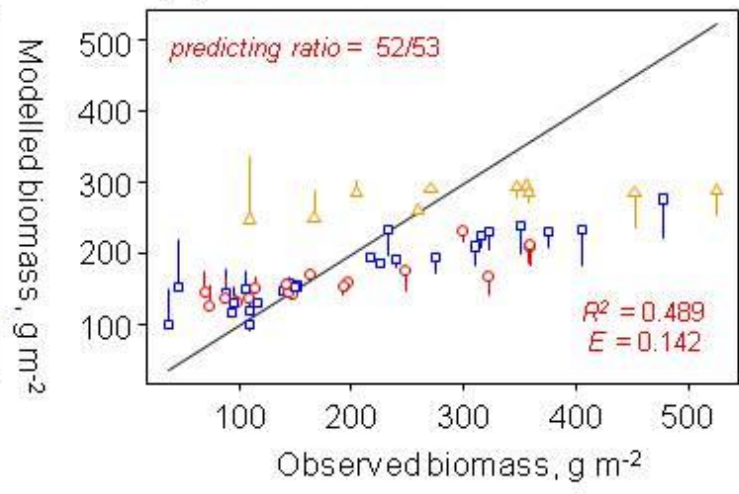

Modelling outcome of an a priori clustering of species based on 4-functional groups defined by Tilman et al. 2001: legumes, forbs, C3- and C4-grasses

(c)

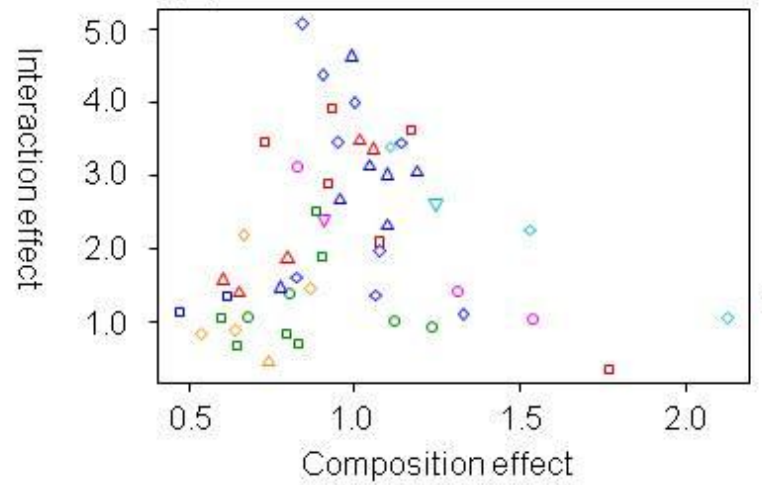

(d)

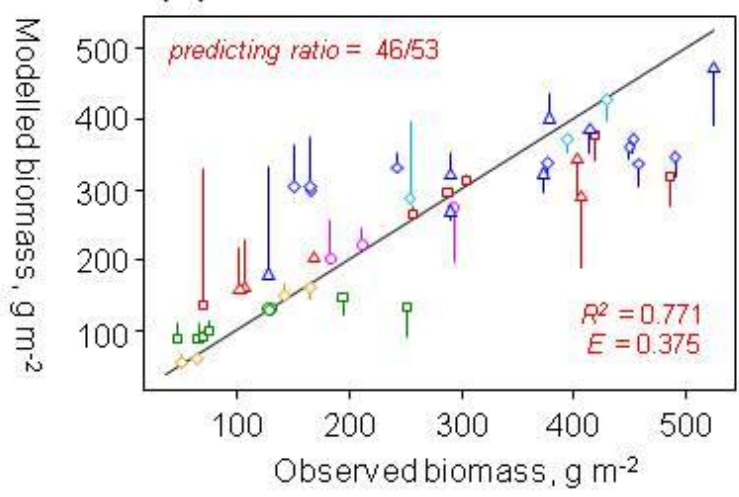

Modelling outcome of an a posteriori 3-group clustering of species

(e)

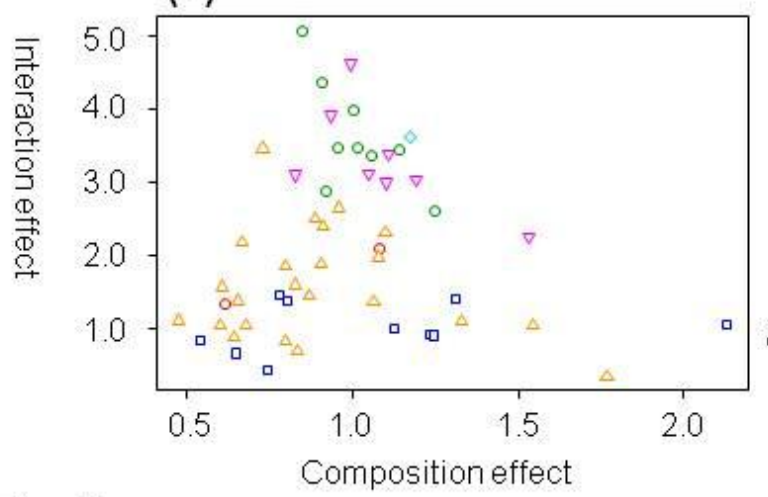

Fig. 6 (f)

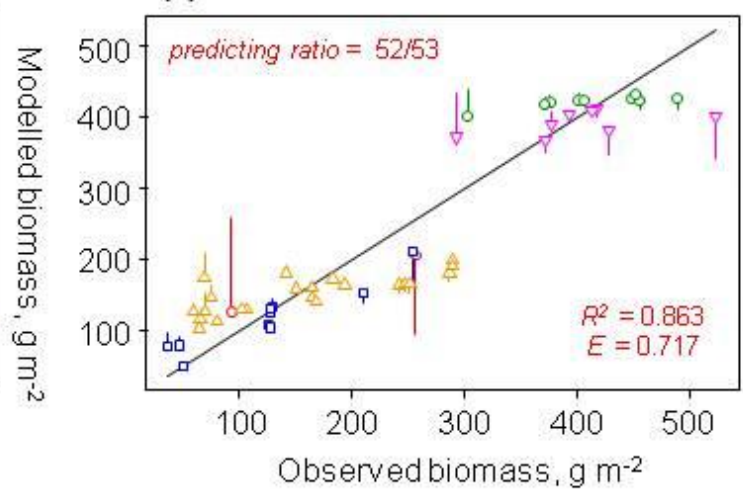

This article is protected by copyright All rights reserved. 